\title{
A Methodological Study to Develop a Standard Operational Protocol for Nurses on Central Line Catheter Care of Patients in Selected Intensive Care Units
}

\author{
Rashmita Devi, Sandhya Ghai, Neena Vir Singh, G. D. Puri' \\ Department of Nursing, National Institute of Nursing Education, PGIMER, 'Department of Anaesthesia, PGIMER, Chandigarh, India
}

Abstract

\begin{abstract}
Aim: This study aims to develop a standard operational protocol (SOP) for central line catheter care for nurses. Materials and Methods: A preliminary draft of protocol based on extensive review of the literature was developed. The current practices of the nurses regarding central line catheter care were observed. Focus group discussions (FGD) were conducted with the nurses to identify the problems encountered by them during care of central line. Four rounds of Delphi were conducted to validate the protocol. The protocol was found to be feasible in terms of understanding, clarity and easy implementation after conducting a pilot study. An observation checklist was developed from the final draft of the protocol. The nurses were taught regarding the central line catheter care as per the protocol. 30 nurses were observed during central line catheter care by the researcher. After implementation of the protocol, feedback of the nurses was taken by conducting FGDs. Results: Content validity index of each item in the protocol was acceptable. The overall Cronbach's alpha value of the checklist was 0.75 . It was concluded that the checklist is reliable and each item has a contribution in the checklist. Conclusion: This protocol addresses interventions to enable staff to provide proper care of the central line catheter to prevent CLABSI.
\end{abstract}

Keywords: Central line care, Intensive Care Units, protocol for nurses

\section{INTRODUCTION}

Venous access is one of the most basic yet critical components of patient care. Safe and reliable venous access is an important issue in daily practice. There are various options for venous access such as peripheral venous access devices, midline catheters, and central venous access devices. ${ }^{[1,2]}$

Although central venous catheter (CVC) enables the administration of life supportive medications and the therapies, the presence of these catheters places patient at risk of various complications. Arterial puncture, hematoma, and pneumothorax are the most common mechanical complications reported during the insertion of CVCs.

In one trial, catheter-related thrombosis occurred in $21.5 \%$ of the patients with femoral venous catheters and $1.9 \%$ of those with subclavian venous catheters $(P<0.001) .{ }^{[3]}$

Central line-associated bloodstream infection (CLABSI) is one of the most significant complications of CVC placement.

\begin{tabular}{|l|l|}
\hline \multicolumn{3}{|c|}{ Access this article online } \\
\hline Quick Response Code: & Website: \\
& www.ijccm.org \\
& \\
&
\end{tabular}

It significantly increases the mortality, morbidity as well as the hospital cost. According to 2011 Centers for Disease Control and Prevention vital signs report, there are approximately 41,000 CLABSIs in acute care hospitals each year. In 2009, about 18,000 CLABSIs occurred in patients in intensive care units (ICUs). ${ }^{[4]}$

The main objective of central line care is to reduce the catheter-related blood stream infection. Health-care workers' hands are the most common vehicle for the transmission of health care associated pathogens. In 2006, advanced draft guidelines on "Hand Hygiene in Health Care" were published and a suite of implementation tools were developed and tested. ${ }^{[5]}$

\section{Address for correspondence: Ms. Rashmita Devi, P. 0. Gameri, Sonitpur - 784 172, Assam, India. E-mail: rashmitadahal@gmail.com}

This is an open access article distributed under the terms of the Creative Common Attribution-NonCommercial-ShareAlike 3.0 License, which allows others to remix, tweak, and build upon the work non-commercially, as long as the author is credited and the new creations are licensed under the identical terms.

For reprints contact: reprints@medknow.com

How to cite this article: Devi R, Ghai S, Singh NV, Puri GD. A methodological study to develop a standard operational protocol for nurses on central line catheter care of patients in selected intensive care units. Indian J Crit Care Med 2017;21:483-7. 
In one meta-analysis of eight randomized trials by Chaiyakunapruk et al. in 2002, it was found that the use of chlorhexidine rather than povidone iodine aqueous solution significantly reduced catheter-related bloodstream infections by approximately $50 \%{ }^{[6]}$

In a systematic review by Gillies et al. in 2004, replacing administration sets no more frequently than $72 \mathrm{~h}$ after initiation of use was found to be safe and cost-effective. A multiple-approach prevention strategy, targeted at the insertion and maintenance of vascular access, can decrease rates of vascular access infections. ${ }^{[7]}$

\section{Aim}

The aim of the study was to develop standard guidelines for nurses on central line catheter care.

\section{Materials and Methods}

The plan for data collection was in the following five phases: In preparation phase, literature was reviewed related to standard practices regarding central line catheter care in ICUs through books, national and international journals, manuals, and web search. Nurses were observed while caring for a patient with central line catheter during morning and evening shifts. Six focus group discussions (FGDs) were conducted with the bedside nurses in the ICUs to assess the problems faced by them during care of central line and collection of their suggestions to overcome these problems. Item pool was generated through assessing the current practices, FGD, and literature review to obtain preliminary draft of protocol. The preliminary draft was formulated for Delphi rounds. A panel consisting of 9 faculty members from the field of nursing and medical was formulated. The formulated protocol was circulated among experts for further refinement of the protocol until common consensus was achieved. First Tryout was carried out to assess the feasibility and practicability of the developed protocol. The modified standard operational protocol (SOP) for central line catheter care was circulated again among the Delphi panelist. Nurses were trained according to developed SOP for central line catheter care with the help of demonstration, posters, and booklets. Feedback of all bedside nurses regarding the protocol was evaluated by conducting five FGDs for further recommendations. The final draft of SOP on central line catheter care was submitted to all selected ICUs in the form of booklet and posters of SOPs. Ethical approval for the study was obtained from the Institute Ethical Committee. Informed written consent was taken from the subjects. Anonymity and confidentiality of the participants were taken care of and protected while reporting the study.

\section{REsULTS}

Data analysis and interpretation were done by Microsoft Excel and SPSS version 21 (IIBM Corporation). The assessment of current practices: The majority of the nurses performed hand washing and maintaining the barrier precautions before accessing CVC. One hundred percent of the nurses changed infusion lines, multiflow adapters, caps, and blood products set according to protocol. About $91.66 \%$ practiced changing of extension and high-pressure lines after $72 \mathrm{~h}$. Changing of burrette set and tegaderm dressing according to the protocol was least practiced (58\% and 50\% respectively). One hundred percent of nurses performed securing IV lines attached to CVC. 91.66\% nurses performed covering the lumens with sterile gauze. Nearly, $83.33 \%$ of the nurses clamped the unused CVC lumen. Wiping of the CVC lumen and port before and after use was least practiced, i.e. $0 \%$. Almost all the steps of changing the dressing of CVC were performed by the $80 \%$ of nurses. Wearing mask while performing dressing change, hand hygiene after removing old dressing and documentation of the procedure were less practiced $(<50 \%)$.

FGDs were conducted with the nurses in the ICUs to assess the problems faced by them during care of central line and collection of their suggestion to overcome these problems. A total of 50 nurses were included from all the selected ICUs in the FGDs.

The problems of the staff nurses regarding caring for a patient with central line were: There is no any written guideline or protocol for central line catheter care. The nurse patient ratio is inadequate which is 1:3. The essential articles required for giving proper care to the patient are not supplied. In service education on prevention of hospital acquired infection have not been conducted in the ICUs. Coordination between the health-care workers is lacking in critical care setting making the care difficult.

Content validity of the developed protocol was analysed using content validity index (CVI). CVI of the final draft of SOP was calculated. CVI of the items of the SOP was $100 \%$ indicating all the Delphi experts have agreed for each item except 1 item whose CVI was 85.4\%. The Cronbach's alpha was used to find out the internal consistency reliability of present checklist prepared from final draft of SOP. The sample size for analysis was 30 . Tables 1-4 show the internal consistency of the items of the tools. There were total 43 items in the checklist and the overall Cronbach's alpha coefficient of the developed checklist was 0.75 , which indicates the reliability and internal consistency of checklist. Corrected item to the total score was applied on all the 43 items of the checklist. Four items in the checklist had zero variance, so those were deleted from the list. Twenty-five items in the checklist had an item score to total score correlation between 0.2 and 0.9 whereas 14 items in the checklist showed item correlation $<0.2$ showing incompatibility with the overall checklist.

To check the individual contribution of items each item was deleted one by one to see the changes in the value of Cronbach's alpha coefficient. Six items in the checklist showed an increase in the value of Cronbach's alpha. Other 33 items did not show increase in the value. It indicates all 33 items had individual significant contribution to the tool.

After discussion with all the Delphi panelists researcher came to a conclusion that the all the items has significance in the 


\begin{tabular}{lccc}
\hline \multicolumn{3}{l}{ Table 1: Reliability of items of checklist for hand washing and maintenance of barrier precautions $(\boldsymbol{n}=\mathbf{3 0})$} \\
\hline Items & $\begin{array}{c}\text { Scale mean if } \\
\text { item deleted }\end{array}$ & $\begin{array}{c}\text { Corrected item-total } \\
\text { correlation }\end{array}$ & $\begin{array}{c}\text { Cronbach's alpha } \\
\text { if item deleted }\end{array}$ \\
\hline Hand washing before accessing CVC & 25.11 & 0.23 & 0.74 \\
Hand washing before donning gloves & 25.14 & 0.40 & 0.73 \\
Hand washing after removing gloves & 25.07 & 0.31 & 0.74 \\
Maximal barrier precautions while handling CVC & 25.15 & 0.21 & 0.74 \\
\hline
\end{tabular}

CVC: Central venous catheter

\begin{tabular}{|c|c|c|c|}
\hline Items & $\begin{array}{l}\text { Scale mean if } \\
\text { item deleted }\end{array}$ & $\begin{array}{l}\text { Corrected item-total } \\
\text { correlation }\end{array}$ & $\begin{array}{l}\text { Cronbach's alpha } \\
\text { if item deleted }\end{array}$ \\
\hline Type of dressing & 24.63 & $0.16^{*}$ & 0.74 \\
\hline CVC dressing $>7$ days & 25.49 & $0.16^{*}$ & 0.74 \\
\hline Replacement of blood product set after $24 \mathrm{~h}$ & 25.74 & $-0.49^{*}$ & 0.77 \\
\hline Burrette set $>72 \mathrm{~h}$ & 25.67 & 0.26 & 0.74 \\
\hline Burrette set changed after $72 \mathrm{~h}$ & 25.59 & 0.32 & 0.73 \\
\hline Infusion line $>24 \mathrm{~h}$ & 24.97 & 29 & 0.74 \\
\hline Infusion line changed after $24 \mathrm{~h}$ & 25.19 & 0.29 & 0.73 \\
\hline Multi flow adapter $>72 \mathrm{~h}$ & 25.44 & 0.56 & 0.71 \\
\hline Multi flow adapter changed after $72 \mathrm{~h}$ & 25.40 & 0.37 & 0.73 \\
\hline Caps $>72 \mathrm{~h}$ & 25.40 & 0.63 & 0.71 \\
\hline Caps changed after $72 \mathrm{~h}$ & 25.48 & 0.60 & 0.71 \\
\hline High pressure line $>72 \mathrm{~h}$ & 25.70 & 0.42 & 0.73 \\
\hline
\end{tabular}

*At 0.05 level of significance. CVC: Central venous catheter

\begin{tabular}{|c|c|c|c|}
\hline Items & $\begin{array}{l}\text { Scale mean if } \\
\text { item deleted }\end{array}$ & $\begin{array}{l}\text { Corrected item-total } \\
\text { correlation }\end{array}$ & $\begin{array}{l}\text { Cronbach's alpha } \\
\text { if item deleted }\end{array}$ \\
\hline Clean luer connector before administering drug & 25.67 & 0.31 & 0.73 \\
\hline IV secured to the patient & 25.11 & 0.29 & 0.74 \\
\hline Wipes lumen before use & 25.40 & 0.48 & 0.72 \\
\hline Wipes lumen after use & 25.59 & 0.44 & 0.72 \\
\hline Wipes sample port before use & 25.81 & $-0.14 *$ & 0.75 \\
\hline Wipes sample port after use & 25.89 & $0.08^{*}$ & 0.74 \\
\hline Clamps unused CVC lumen & 25.03 & $-0.04 *$ & 0.74 \\
\hline Checks of patency of the ports & 25.44 & $-0.09^{*}$ & 0.77 \\
\hline Covers the hubs and lumens of CVC with gauze & 25.07 & 0.37 & 0.73 \\
\hline Changes gauze every 6 hourly & 25.29 & 0.29 & 0.73 \\
\hline
\end{tabular}

*At 0.05 level of significance. CVC: Central venous catheter; IV: Intravenous

checklist despite the increased value of Cronbach's alpha after their deletion. Average scale mean was 26.00. When scale mean if item deleted was applied on 39 items of checklist, the scale mean if item deleted was in the range of 25.04-25.89 and none of the item showed an increase in the value of average scale mean rather it remained same or decreased. It shows checklist is internally consistent by taking all the items.

After the implementation of the developed protocol feedback of the staff nurses regarding the developed protocol was taken by conducting a series of FGDs. The developed protocol is very beneficial for them for quick reference during their duty. Because of lack of time and inadequate supply of articles, they are not able to provide proper care. There is an improvement in the care of patients with central line after the implementation of the protocol.

\section{Discussion}

SOPs are written procedure prescribed for repetitive use as a practice, in accordance with agreed upon specifications. In an institute, SOP helps in creating an environment of efficiency as well as consistency. The standard protocols in intensive care areas are of significant importance as in these areas patients require a high standard of care.

Central line-based blood stream infection is reported to be the first cause of healthcare associated infections (HAI) in ICUs. 


\begin{tabular}{|c|c|c|c|}
\hline Items & $\begin{array}{l}\text { Scale mean if } \\
\text { item deleted }\end{array}$ & $\begin{array}{l}\text { Corrected item-total } \\
\text { correlation }\end{array}$ & $\begin{array}{l}\text { Cronbach's alpha } \\
\text { if item deleted }\end{array}$ \\
\hline Wears mask & 25.15 & $-0.05^{*}$ & 0.75 \\
\hline Collects required articles & 25.11 & 0.49 & 0.73 \\
\hline Donns sterile gloves & 25.07 & $0.12 *$ & 0.74 \\
\hline Stabilizes the hub while removing old dressing & 25.08 & 0.37 & 0.73 \\
\hline Observes dressing for signs of infection & 25.70 & $0.08 *$ & 0.75 \\
\hline Hand wash & 25.22 & 0.37 & 0.73 \\
\hline Cleans the insertion site & 25.04 & 0.21 & 0.74 \\
\hline Cleans the whole area to be covered by dressing & 25.11 & $0.16^{*}$ & 0.74 \\
\hline Peels off transparent dressing and carefully places over the CVC & 25.07 & $0.03 *$ & 0.74 \\
\hline Disposal of the waste according to bio medical waste management & 25.15 & 0.49 & 0.73 \\
\hline Documents the dressing change of $\mathrm{CVC}$ & 25.49 & 0.33 & 0.73 \\
\hline Labels the CVC dressing with date and time of change & 25.63 & $-0.37 *$ & 0.78 \\
\hline
\end{tabular}

Overall Cronbach's alpha coefficient based on standardized items is 0.75 . *Items in the tool which shows item to total correlation $<0.2$. Overall scale mean is 26.00. CVC: Central venous catheter

In a study done by Malhotra et al. in 2014, an overall HAI prevalence was $8.78 \%$ with highest in ICUs $(33.3 \%)$ followed by pediatric wards $(12.5 \%)$ and surgical wards $(10.3 \%){ }^{[8]}$

The present study was carried out in five phases. Review of literature was done to assess the burden of central line related complications worldwide, recent advances in central line care, guidelines for central line care as well as SOPs for central line care. To know the regular practices of central line care the current practices of nurses were observed. To understand the problems they encounter during the procedure and the possible suggestions, a series of FGDs were conducted. An FGD provides an insight into how a group thinks about an issue, about the range of opinion and ideas, and the inconsistencies and variation that exists in a particular community in terms of beliefs and their experiences and practices. According to the guidelines, the group should not be so large as to preclude adequate participation by most members nor should it be so small that it fails to provide significant greater coverage than that of an individual interview. ${ }^{[9]}$ In this study, researcher conducted all FGDs with group consisting of 8-10 members.

On the basis of literature, current practices and the themes of FGD, a preliminary draft was formulated. For validation of the preliminary draft Delphi technique was employed. The Delphi technique is a widely used and accepted method for gathering data from respondents within their domain of expertise. To ensure heterogenicity of the panel of experts, in the present study, nine members from various fields of medical and nursing science were selected. Similarly, Kaushal et al., in their study to develop nursing checklist for receiving patients, selected 11 panel of experts. ${ }^{[10]}$

Repeated rounds of Delphi are required to reach a common consensus between the panelists. Kirkwood et al. conducted a study to determine nursing research priorities in which they found that three Delphi rounds were sufficient to reach a common consensus. ${ }^{[11]}$ In the present study, four rounds of Delphi were taken to reach a common consensus. The analysis of content validity was done using CVI of the developed protocol. Polit et al. also recommended that CVI is a plausible method of estimating the content validity of a new (or revised) scale. ${ }^{[12]}$ In the present study, the CVI of all the items were $100 \%$ except for 1 item which is $85.4 \%$ indicating the acceptability of the content validity of the protocol.

In the present study, the overall Cronbach's alpha coefficient value of the checklist developed from the final draft of protocol was established at 0.749 , providing the reliability of the protocol. In a similar methodological study by Bandana et al. on the internal consistency of an Audit tool the internal consistency of the tool was checked with Cronbach's alpha coefficient in which value of Cronbach's alpha was 0.73 which indicated the reliability of the protocol. ${ }^{[13]}$

The final draft of the protocol was submitted to all the selected ICUs as well as posters of the protocol were also displayed in the respective ICUs.

\section{CONCLUSION}

Central line based infection is the most significant complication in critical care setting. It is a challenge for the health care system to increase awarness among the nurses regarding the prevention of central line related complications. This protocol addresses interventions to enable staff to provide care of the catheter in order to prevent central line associated blood stream infection.

\section{Financial support and sponsorship}

Nil.

\section{Conflicts of interest}

There are no conflicts of interest.

\section{RefEREnCES}

1. Cheung E, Baerlocher MO, Asch M, Myers A. Venous access: A practical review for 2009. Can Fam Physician 2009;55:494-6.

2. Smeltznner SC, Bare BG, Hinkle JL, Cheever KH. Brunner \& Suddarth's 
Textbook of Medical-Surgical Nursing. $11^{\text {th }}$ ed. USA: Lippincott Williams \& Wilkins Publishers; 2008. p. 816-8.

3. Merrer J, De Jonghe B, Golliot F, Lefrant JY, Raffy B, Barre E, et al. Complications of femoral and subclavian venous catheterization in critically ill patients: A randomized controlled trial. JAMA 2001;286:700-7.

4. Guidelines for the Prevention of Intravascular Catheter Related Infections, 2011 (Centre for Disease Control and Prevention); 2011. Available from: http://www.cdc.gov/vitalsigns. [Last accessed on 2016 Jan 21].

5. World Health Organization. WHO Guidelines for Hand Hygiene in Health Care (Advanced Draft). Geneva: WHO; 2006. Available from: http://www.who.int/gpsc/tools/en/. [Last accessed on 2015 Jan 21].

6. Chaiyakunapruk N, Veenstra DL, Lipsky BA, Saint S. Chlorhexidine compared with povidone-iodine solution for vascular catheter-site care: A meta-analysis. Ann Intern Med 2002;136:792-801.

7. Gillies D, O'Riordan L, Wallen M, Rankkn K, Morrison A. Timming of intravascular administration set changes, a systematic review.Infect Control Hosp Epidemiol 2004;25:240-50. Available from: http;//www. ncbi.nlm.nih.gov [Last accessed on 2017 Jan 21].
8. Malhotra S, Sharma S, Hans C. Prevalence of hospital acquired infections in a tertiary care hospital in India. Int Invent J Med Med Sci 2014;1:91-4. Available from: http://www.internationalinventjournals. org/journals/IIJMMS. [Last accessed on 2016 Jan 21].

9. Wong LP. Focus group discussion: A tool for health and medical research. Singapore Med J 2008;49:256-60.

10. Kaushal RK, Kapoor S, Kaur S, Bhagat H. A methodological study to develop a 'nursing checklist' for receiving patients in ICUs. Nurs Midwifery Res J 2015;11:1-11. Available from: http;//www.medind.nic. jn [Last cited on 2016 Mar 21].

11. Kirkwood M, Wales A, Wilson A. A Delphi study to determine nursing research priorities in North Glasgow university hospitals. Int J Nurs Stud 2005;43:560-6.

12. Polit DF, Beck CT, Owen SV. Is the CVI an acceptable indicator of content validity? Appraisal and recommendations. Res Nurs Health 2007;30:459-67.

13. Bandana B, Walia I, Saini SK. Development of audit tool: A methodological study for auditing the family health records. Nurs Midwifery Res J 2009;5:166-75. 